\title{
Salvage radiotherapy for macroscopic local recurrences after radical prostatectomy
}

\author{
A national survey on patterns of practice
}

\author{
Alan Dal Pra ${ }^{1}$ Cedric Panje C Thomas Zilli $^{3}$ - Winfried Arnold ${ }^{4}$ Kathrin Brouwer $^{5}$ Helena Garcia $^{6}$ •

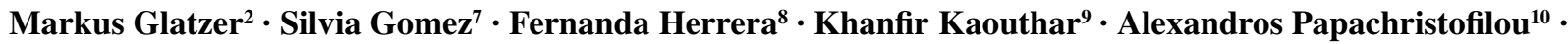 \\ Gianfranco Pesce ${ }^{11} \cdot$ Christiane Reuter $^{12} \cdot$ Hansjörg Vees $^{13} \cdot$ Daniel Rudolf Zwahlen ${ }^{14} \cdot$ Daniel Engeler $^{15}$ • \\ Paul Martin Putora ${ }^{2}$
}

Received: 30 March 2017 / Accepted: 13 June 2017 / Published online: 27 June 2017

(C) Springer-Verlag GmbH Deutschland 2017

\begin{abstract}
Introduction Although salvage radiotherapy (SRT) for PSA recurrence after radical prostatectomy provides better oncological outcomes when delivered early, in the absence of detectable disease many patients are treated for macroscopic locally recurrent tumors. Due to limited data from prospective studies, we hypothesized an important variability in the SRT management of these patients. Our aim was to investigate current practice patterns of SRT for local macroscopic recurrence after radical prostatectomy.

Material and methods A total of 14 Swiss radiation oncology centers were asked to complete a survey on treatment specifications for macroscopic locally recurrent disease including information on pretherapeutic diagnostic procedures, dose prescription, radiation delivery techniques and androgen deprivation therapy (ADT). Treatment rec-
\end{abstract}

Alan Dal Pra and Cedric Panje have contributed equally to this manuscript.

$\triangle$ Dr. Alan Dal Pra

alan.dalpra@insel.ch

1 Department of Radiation Oncology, Bern University Hospital, Inselspital Bern, Freiburgstrasse, 3010 Bern, Switzerland

2 Department of Radiation Oncology, Kantonsspital St. Gallen, St. Gallen, Switzerland

3 Department of Radiation Oncology, Hospitaux Universitaires de Génève, Génève, Switzerland

4 Department of Radiation Oncology, Luzerner Kantonsspital, Luzerner, Switzerland

5 Department of Radiation Oncology, Stadtspital Triemli, Zürich, Switzerland

6 Department of Radiation Oncology, Universitätsspital Zürich, Zürich, Switzerland ommendations on ADT were analyzed using the objective consensus methodology.

Results The majority of centers recommended pretreatment magnetic resonance imaging (MRI) of the pelvis and choline positron emission tomography (PET). The median prescribed dose to the prostate bed was 66 Gy (range $65-72 \mathrm{~Gy}$ ) with a boost to the macroscopic lesion used by $79 \%$ of the centers with a median total dose of $72 \mathrm{~Gy}$ (range 70-80 Gy). Intensity-modulated rotational techniques were used by all centers and daily cone beam computed tomography (CT) was recommended by $43 \%$. The use of concomitant ADT for any macroscopic recurrence was recommended by $43 \%$ of the centers while the remaining centers recommended it only for high-risk disease, which was not consistently defined.

7 Department of Radiation Oncology, Kantonsspital Aarau, Aarau, Switzerland

8 Department of Radiation Oncology, Centre Hospitalier Universitaire Vaudois, Lausanne, Switzerland

9 Department of Radiation Oncology, Hôpital du Valais, Sion, Switzerland

10 Department of Radiation Oncology, Universitätsspital Basel, Basel, Switzerland

11 Department of Radiation Oncology, EOC Bellinzona, Bellinzona, Switzerland

12 Department of Radiation Oncology, Kantonsspital Münsterlingen, Münsterlingen, Switzerland

13 Department of Radiation Oncology, Klinik Hirslanden, Zürich, Switzerland

14 Department of Radiation Oncology, Kantonsspital Graubünden, Chur, Switzerland

15 Department of Urology, Kantonsspital St. Gallen, St. Gallen, Switzerland 
Conclusion We observed a high variability of treatment paradigms when SRT is indicated for macroscopic local recurrences after prostatectomy. These data reflect the need for more standardized approaches and ultimately further research in this field.

Keywords Postoperative radiotherapy · Salvage radiotherapy · Prostate cancer · Radiotherapy · Macroscopic recurrence

\section{Salvage-Radiotherapie bei makroskopischen Lokalrezidiven nach radikaler Prostatektomie}

Nationale Umfrage zu Behandlungsmustern

\section{Zusammenfassung}

Einleitung Obwohl die Evidenz für eine frühzeitige Salvage-Radiotherapie (SRT) bei einem PSA-Rezidiv nach radikaler Prostatektomie spricht, werden viele Patienten erst bei einem makroskopischen Lokalrezidiv behandelt. Hier scheint es jedoch aufgrund der fehlenden Daten aus prospektiven Studien eine Variabilität der Behandlungskonzepte zu geben. Das Ziel der Studie war es, die aktuelle Behandlungspraxis in der SRT des makroskopischen Rezidivs eines Prostatakarzinoms zu untersuchen.

Material und Methoden Insgesamt 14 Schweizer Strahlentherapiezentren wurden für eine Umfrage zu den Behandlungsparametern beim makroskopischen Lokalrezidiv eines Prostatakarzinoms kontaktiert und nach diagnostischen Maßnahmen, Dosisverschreibung, Strahlentherapietechniken und antihormoneller Therapie (ADT) befragt. Die variierenden Indikationen zur ADT wurden mittels der Objective-konsensus-Methodologie ausgewertet.

Ergebnisse Die Mehrheit der Zentren empfahl vor der Therapie eine Magnetresonanztomographie (MRT) des Beckens und eine Cholin-Positronenemissionstomographie (PET). Die mediane verschriebene Dosis für die Prostataloge war 66 Gy (65-72 Gy) mit einem Boost auf das makroskopische Lokalrezidiv in $79 \%$ der Zentren bis zu einer medianen Dosis von 72 Gy (70-80Gy). Alle Zentren verwendeten intensitätsmodulierte Rotationstechniken, ein tägliches Cone-beam-CT wurde in $43 \%$ der Zentren empfohlen. Eine begleitende ADT wurde von $43 \%$ für jedes makroskopische Lokalrezidiv empfohlen, während die übrigen Zentren dies nur bei Hochrisikogruppen (mit unterschiedlichen Definitionen) durchführten.

Schlussfolgerung Es wurde eine hohe Variabilität der Behandlungskonzepte für die SRT des makroskopischen Lokalrezidivs nach Prostatektomie beobachtet. Dies zeigt den Bedarf an standardisierten Behandlungskonzepten und weiteren Studien in diesem Bereich auf.
Schlüsselwörter Postoperative Strahlentherapie · SalvageRadiotherapie · Prostatakarzinom · Strahlentherapie · Makroskopisches Rezidiv

\section{Introduction}

After radical prostatectomy up to $40 \%$ of prostate cancer (PCa) patients develop a biochemical relapse within 10 years [1] and the predominant site of relapse is local [2]. Salvage radiotherapy (SRT) is the only potentially curative therapy for these patients. Current best evidence shows better oncological outcomes when postoperative radiotherapy is delivered earlier in the course of the disease either as adjuvant treatment [3-5] or as early salvage [6] but the optimal timing is often debated [7]. In an attempt to avoid potential overtreatment, some physicians opt for a vigilant approach offering SRT solely at the first evidence of macroscopic relapse. Additionally, novel imaging modalities, such as multiparametric magnetic resonance imaging (mpMRI) and positron emission tomography/computed tomography (PET/CT) have been increasingly used and may detect macroscopic recurrence at low prostate-specific antigen (PSA) levels [8]; therefore, the number of patients with detectable disease in the prostatic fossa is deemed relevant, and an increase is foreseen over the coming years due to better imaging tools.

Many strategies to optimize postoperative radiotherapy have been addressed in randomized trials, including dose escalation, elective treatment of pelvic nodes and use of androgen deprivation therapy (ADT) [9-12]; however, detectable disease in the prostate bed has not been markedly addressed in prospective studies. The aim of this study was to assess national patterns of practice in the radiotherapy management of patients with detected local recurrence in the prostate bed.

\section{Methods}

All Swiss university hospitals and radiation oncology centers that previously participated in the Swiss Group for Clinical Cancer Research (SAKK) prospective study (SAKK 09/10) to test dose-escalated salvage radiotherapy for biochemically recurrent disease [10] were contacted. They were asked to provide the following institutional treatment specifications for macroscopically recurrent disease: pretherapeutic diagnostic procedures, target volume definitions and planning target volume (PTV) margins, radiotherapy dose prescription, use of ADT, radiation delivery techniques and protocol as well as the recommendations and dose to the pelvic lymph nodes. Each institutional treatment recommendation was collected as free unrestricted 
text until January 2017. Treatment recommendations regarding the use of ADT were additionally analyzed using the objective consensus methodology as previously described [13, 14]. Data were converted into center-specific decision trees and reviewed with the participants for an accuracy check. Individual treatment algorithms were compared semi-automatically and then analyzed for consensus and controversies. The level of consensus was determined by the number of participants recommending the most common treatment divided by the number of participants.

\section{Results}

A total of 14 Swiss radiation oncology centers were contacted. All participating centers returned the questionnaire by January 2017. The results are summarized in Tables 1-2 and Figs. 1, 2, 3.

Pretreatment diagnostics included PSA testing and MRI of the pelvis in all centers. Choline-PET was routinely utilized by $86 \%$ of the centers, and the median PSA threshold for the requisition of choline-PET was $1 \mathrm{ng} / \mathrm{ml}$ (range $0.5-2 \mathrm{ng} / \mathrm{ml}$ with $83 \%$ of the centers using a threshold $\geq 1 \mathrm{ng} / \mathrm{ml}$ ). Additionally, three centers (21\%) recommended choline-PET based on a PSA doubling-times lower than 6 months. Prostate-specific membrane antigen (PSMA) PET imaging was routinely used in only one department and occasionally used in three institutions (21\%), with a PSA threshold ranging from 0.2 to $0.7 \mathrm{ng} / \mathrm{ml}$. A biopsy of the radiologically detected recurrence(s) was considered in selected cases by 4 centers $(29 \%)$, but no center performed routine biopsies. At the evidence of macroscopic disease in the prostate bed, a restaging bone scan was routinely recommended by 2 centers $(14 \%)$ regardless of the PSA value.

The prostate bed target volume was contoured according to the Radiation Therapy Oncology Group (RTOG) guidelines [15] in $14 \%$ of the centers, according to the European Organisation for Research and Treatment of Cancer (EORTC) guidelines [16] in 43\%, and adapted according to institutional guidelines in $43 \%$. A median clinical target volume (CTV) to planning target volume (PTV) margin of $7 \mathrm{~mm}$ (range $3-15 \mathrm{~mm}$ ) was recommended for the prostate bed. The median dose to the prostate bed was $66 \mathrm{~Gy}$ (range 65-72 Gy). Additionally, a boost to the macroscopic recurrence was performed by $79 \%$ of the centers with a median total dose of 72 Gy (range 70-80 Gy) (Fig. 1). Normal fractionation ( $2 \mathrm{~Gy}$ per fraction) was used by all centers.

The delineation of the macroscopic lesion on the planning CT scan was based on the available imaging modality, mostly pelvic MRI used for co-registration. Of the centers $45 \%$ that used a boost to the macroscopic lesion defined the gross target volume (GTV) based on MRI alone, $45 \%$ based
Table 1 Summary of recommendations on pretreatment diagnostics and radiation treatment details for local macroscopic recurrence after radical prostatectomy

\begin{tabular}{|c|c|}
\hline & Recommendations \\
\hline \multirow[t]{5}{*}{ Diagnostic method } & $100 \%$ serum PSA level \\
\hline & $\begin{array}{l}86 \% \text { choline PET (median PSA threshold } \\
1 \mathrm{ng} / \mathrm{ml} \text {, range } 0.2-2 \mathrm{ng} / \mathrm{ml} \text { ) }\end{array}$ \\
\hline & $\begin{array}{l}29 \% \text { PSMA PET (median PSA threshold } \\
0.2 \mathrm{ng} / \mathrm{ml} \text {, range } 0.2-0.7 \mathrm{ng} / \mathrm{ml} \text { ) }\end{array}$ \\
\hline & $14 \%$ bone scan \\
\hline & $29 \%$ biopsy in selected cases \\
\hline \multirow{3}{*}{$\begin{array}{l}\text { Target volume } \\
\text { definition }\end{array}$} & $14 \%$ RTOG-based \\
\hline & $43 \%$ EORTC-based \\
\hline & $43 \%$ institutional adaptation \\
\hline Dose to prostate bed & Median 66 Gy (range 64-72 Gy) \\
\hline $\begin{array}{l}\text { Dose to macro- } \\
\text { scopic tumor }\end{array}$ & Median 72 Gy (range 66-80 Gy) \\
\hline $\begin{array}{l}\text { Dose to pelvic } \\
\text { lymph nodes }\end{array}$ & Median 50 Gy (range 45-50.4 Gy) \\
\hline \multirow{4}{*}{$\begin{array}{l}\text { Indications for } \\
\text { elective pelvic node } \\
\text { irradiation } \\
\text { (multiple answers } \\
\text { allowed) }\end{array}$} & $43 \%$ high-risk $^{\mathrm{a}} \mathrm{pN} 0$ \\
\hline & $43 \%$ any $\mathrm{pN} 1$ \\
\hline & $43 \%$ high risk ${ }^{\mathrm{a}} \mathrm{pN} 1$ \\
\hline & $7 \%$ no pelvic RT \\
\hline
\end{tabular}

${ }^{a}$ For the purpose of this study, high-risk for pelvic lymph node metastasis was defined according to the information provided by the centers, which includes D'Amico classification, MSKCC criteria, absence of extended pelvic lymph node dissection, PSA doubling time $<6$ months, Partin tables and Roach score.

$P S A$ prostate-specific antigen, $P E T$ positron emission tomography, MSKCC Memorial Sloan-Kettering Cancer Center, PSMA Prostate-Specific Membrane Antigen, RTOG Radiation Therapy Oncology Group, EORTC European Organisation for Research and Treatment of Cancer, $R T$ Radiotherapy

Table 2 Example for a controversial ADT recommendation in the following clinical situation: macroscopic recurrence of prostate cancer $<1 \mathrm{~cm}$ in size, initial pT3b, Gleason score $\geq 9$, PSA doubling time $>6$ months, recurrence $>1$ year from surgery

\begin{tabular}{ll}
\hline Number of centers & Recommendation \\
\hline 4 & no ADT \\
4 & 6 months ADT \\
1 & 9 months ADT \\
2 & 12 months ADT \\
3 & 36 months ADT \\
\hline
\end{tabular}

$A D T$ androgen deprivation therapy

on MRI and choline-PET and one center based on cholinePET alone. The majority of centers $(82 \%)$ used sequential treatment plans and $18 \%$ used simultaneously integrated boost (SIB) with a daily dose to the macroscopic lesion ranging from $2 \mathrm{~Gy}$ to $2.12 \mathrm{~Gy}$.

All departments used intensity-modulated rotational techniques (IMRT) while 3D-conformal radiotherapy (3DCR) was occasionally considered by one center. Daily image guidance using cone beam CT (CBCT) or mega- 


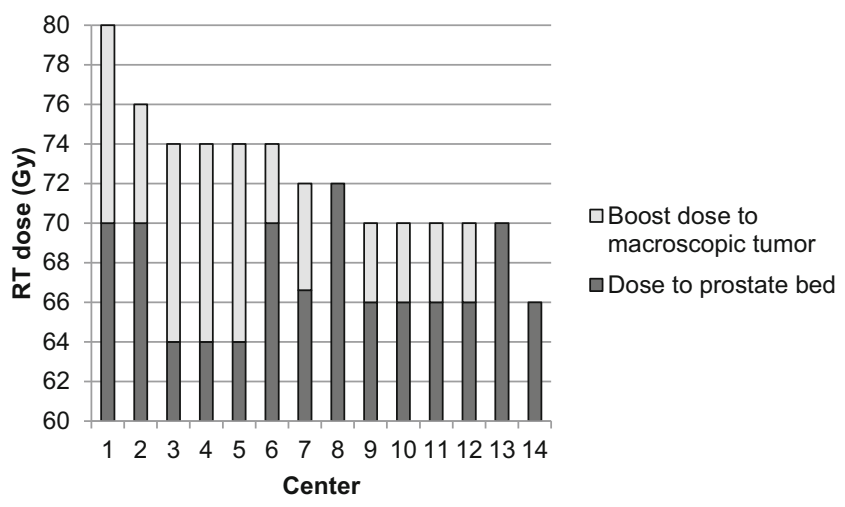

Fig. 1 Radiation dose prescription to the prostate bed (black) and additional boost dose to macroscopically recurrent disease (light grey). Each column represents a treating center $(n=14)$

voltage (MV) CBCT for tomotherapy was performed by $43 \%$ of the centers for the whole treatment course, and by 1 center only for the boost volume. Of the centers $29 \%$ used CBCT 2-3 times weekly and $21 \%$ once weekly. No participating center reported a regular use of fiducial markers for tumor tracking. All centers utilized a bladder filling protocol, $86 \%$ used a specific rectal preparation protocol and 2 centers (14\%) routinely used rectal balloons for simulation and treatment.

Regarding elective irradiation of the pelvic lymph nodes, $43 \%$ of the centers recommended it only in cases of positive node(s) on lymphadenectomy (pN1) irrespective of other risk factors, $43 \%$ recommended pelvic treatment in case of $\mathrm{pN} 1$ and presence of additional risk factors and another $43 \%$ in cases of node-negative disease after surgery (pN0) with risk factors, such as lack of extended lymph node dissection $(n=2)$, Gleason score $\geq 8(n=1)$, Gleason score 9-10 $(n=$ $1)$, pT3b disease $(n=1)$, PSA doubling time $<6$ months $(n=1)$, initial high-risk disease according to the D'Amico classification [17] $(n=2)$ or the Memorial Sloan Kettering Cancer Center (MSKCC) score [18] $(n=1)$, Partin tables [19] $(n=1)$ or Roach score [20] $(n=1)$. One center did not perform pelvic lymph node irradiation independent of the extent of lymph node dissection or other risk factors.
The median prescribed dose to the pelvic nodes was $50 \mathrm{~Gy}$ (range 45-50.4 Gy).

Of the centers $43 \%$ recommended ADT for any macroscopically recurrent disease for a duration of 6 months and $28 \%$ recommended a prolonged ADT duration of 9-36 months for high-risk disease. High-risk disease was defined inconsistently and included initial risk group (D'Amico classification) $(n=2)$, Gleason score $\geq 8(n=$ $4)$, Gleason score $\geq 9(n=4)$, pT3b $(n=3)$, size of macroscopic recurrence $>1 \mathrm{~cm}(n=1)$ and PSA doubling time after surgery $<6$ months $(n=2)$. Recommendations for concomitant ADT were also analyzed using the objective consensus methodology as previously reported [13] and one center was excluded from this analysis as the referring urologists independently prescribed the ADT. A representative mode decision tree showing the most common recommendation for each defined clinical situation is depicted in Fig. 2. The most common recommendation among all combinations of parameters was the use of ADT for 6 months; however, a consensus of $75 \%$ for indications and duration could rarely be reached. An example for the spectrum of recommendations in a clinical situation without consensus is shown in Table 2. The individual institutional decision criteria for the indications and duration of ADT are shown in Fig. 3.

\section{Discussion}

This survey demonstrates significant variability in the radiotherapy management of PCa patients with macroscopic, locally recurrent tumors after radical prostatectomy. Among Swiss centers, there are different criteria for pretreatment diagnostics and imaging, radiation dose to prostate bed and macroscopic disease, indications and dose to the pelvic lymph nodes, and use of ADT.

Randomized clinical trials have shown the improvement in biochemical relapse-free survival for adjuvant radiotherapy after prostatectomy in patients with adverse pathological features [3-5, 21]. Despite an improvement in overall

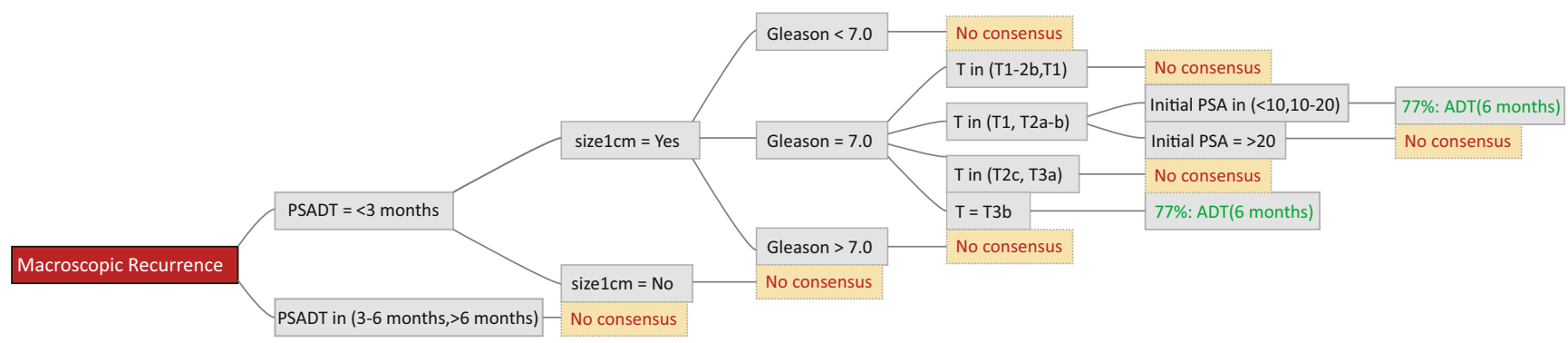

Fig. 2 The mode recommendation tree shows combinations of parameters that lead to a 75\% consensus on the indications and duration of ADT. In all cases the recommendation ( $>75 \%$ ) was 6 months of androgen deprivation therapy (PSADT PSA doubling time, size $1 \mathrm{~cm}$ size of lesion $\geq 1 \mathrm{~cm}$, Gleason Gleason score, $T$ T category, initial PSA preoperative prostate-specific antigen) 
Fig. 3 Decision criteria for the use and duration of androgen deprivation therapy (ADT) with salvage radiotherapy for macroscopically recurrent prostate cancer. Institutional decision factors for the indication and duration of ADT for each center are highlighted in grey. One center was excluded from analysis as the decision criteria varied depending on the referring urologist

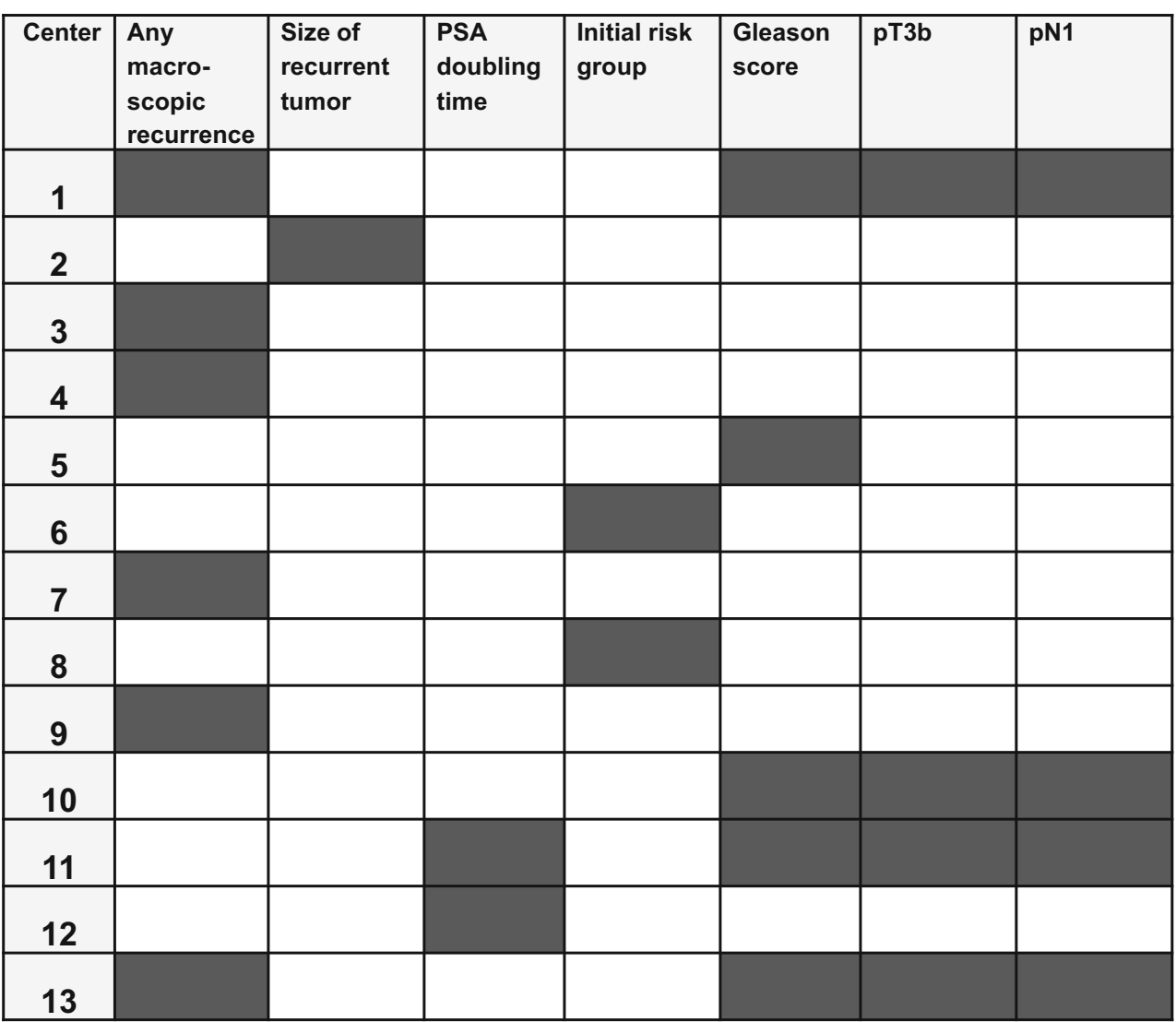

survival in the Southwest Oncology Group (SWOG) 8794 trial [4], the use of adjuvant radiotherapy is not universally implemented. Many clinicians offer SRT to patients with biochemical progression instead of adjuvant radiotherapy in order to avoid potential overtreatment, even in the presence of high-risk features [22]. The use of early SRT instead of adjuvant radiotherapy is being addressed in ongoing clinical trials (RADICALS, NCT00541047 and RAVES, NCT00860652).

The SRT constitutes the only established potentially curative therapy for patients with biochemical recurrence. It has been associated with improvement in distant metastasisfree survival, disease-specific survival and overall survival, and outcomes are better when SRT is delivered early and at low PSA levels [23]. In more contemporary series, an undetectable PSA using ultra-sensitive assays was associated with lower risk of relapse and consequently less possible benefit from adjuvant radiation. Conversely, SRT efficacy is indeed higher with an earlier detection of PSA relapse; therefore, early SRT is recommended in most international treatment guidelines [24, 25].

Choline PET and PSMA PET can often be used to identify early recurrences not revealed by traditional imaging modalities (e.g. bone scan, CT scan). Sobol et al. [26] used mpMRI and choline PET to map early patterns of relapse in 202 postsurgery patients not exposed to radiation or ADT. At a median PSA of $2.3 \mathrm{ng} / \mathrm{ml}$ (interquartile range IQR 1.4-5.5), 33\% exhibited local only, 22\% local plus metastatic and $45 \%$ metastatic only relapse. Pelvic node only relapse was observed in $19 \%$. This shows that new imaging modalities could reveal an anatomically diverse pattern of recurrence and possibly guide treatment decisions more accurately, therefore challenging current treatment standards in the absence of visible disease on traditional imaging. Additionally, pre-PET PSA levels and PSA doubling time predict PSMA PET positivity [27]. This survey shows that the majority of centers perform metabolic imaging at the evidence of macroscopic recurrence in the prostate bed. Nevertheless, there is an important variation in the use and indication criteria for choline-PET and/or PSMA PET in Swiss centers. This is likely explained by the specific availability of each method (PSMA PET started to be regularly reimbursed in Switzerland after January 2017) as well as the evolving evidence on imaging in PCa management. Nevertheless, further validation of these novel imaging methods is essential to demonstrate the actual clinical benefits and cost-effectiveness of these approaches.

The elective treatment of pelvic nodes has been debated for a long time in PCa radiotherapy without a clear proof of benefits $[28,29]$. In the salvage setting, the results of RTOG 0534 (NCT00567580) comparing SRT alone versus SRT plus short-term ADT versus SRT, short-term ADT 
and pelvic lymph node radiotherapy are eagerly awaited. Our survey reflects the uncertainties in the use of elective radiation to the pelvic nodes [30]. Of the participating centers $43 \%$ responded that they treat the pelvis according to the presence of high-risk disease (a definition that was not uniform), the presence of $\mathrm{pN} 1$ or according to the extent of previous lymph node dissection. The latter is an interesting finding given the fact that lymphadenectomy has never been prospectively proven to add any clinical benefit [31]. Another important question in patients with macroscopic recurrence is the use of elective treatment to the whole prostate bed according to established contouring guidelines $[15,16]$. To the best of our knowledge, adaptive SRT volumes solely to the site of macroscopic recurrence have never been prospectively addressed and could be an alternative to improve the therapeutic ratio.

The use of ADT combined with primary radiotherapy improves overall survival based on large prospective trials [32]. For patients with biochemical recurrence after surgery, the RTOG 9601 trial (NCT00002874) showed a 5\% increase in 10-year overall survival (hazard ratio HR: 0.75 ; $95 \%$ confidence interval CI: $0.58-0.98$ ) when patients were treated with SRT plus 2 years of bicalutamide [11]. Subgroup analyses showed the greatest benefits in patients with more aggressive disease and PSA higher than $1.5 \mathrm{ng} / \mathrm{ml}$. Improved outcomes were also observed in the GETUG-16 trial (NCT00423475). Men with biochemical failure treated with SRT plus 6 months of luteinizing hormone-releasing hormone (LHRH) agonist had a 17.5\% improvement in 5-year progression-free survival (HR: 0.50, 95\% CI 0.38-0.66; $p<0.0001)$ [33]. Although the RADICALS study (NCT00541047) will hopefully shed further light on the role of ADT in the postoperative setting, in the context of macroscopic disease, we may extrapolate the results of previous trials, such as RTOG 9601 and GETUG 16; however, many questions still remain on the indication, timing and treatment duration.

In terms of radiation dose, retrospective studies suggest that there is a dose-response effect in the salvage setting, in the absence of macroscopic disease [34]. The SAKK 09/10 trial [10] in which patients were randomized to SRT with 64 Gy versus 70 Gy demonstrated low rates of acute toxicity and minor impact on the quality of life for dose escalation; however, oncological outcomes are still awaited. In the context of macroscopic recurrence our survey has shown an important variation in dose prescriptions. The median doses to the prostate bed and macroscopic recurrence were $66 \mathrm{~Gy}$ and $72 \mathrm{~Gy}$, respectively, with one center reaching a final total dose of $80 \mathrm{~Gy}$. Genitourinary toxicity may be further increased with dose escalation despite the use of IMRT. In a retrospective study where most patients were treated with doses $\geq 70 \mathrm{~Gy}$, no differences in genitourinary toxicity were seen between IMRT versus 3DCRT [35]. An important ret- rospective study using IMRT and 76 Gy to the prostate bed showed a 5-year risk of grade 2-3 genitourinary toxicity of $22 \%$ and a 5 -year risk of grade $2-3$ gastrointestinal toxicity of $8 \%$ [36]. Other authors have shown that IMRT allows further dose escalation by reducing the dose to adjacent normal tissues with decrease morbidity [37]. Prospective randomized trials evaluating patient reported outcomes will allow us to derive definitive conclusions regarding the benefits and potential harms of dose escalated treatment.

Some of the participating centers used SIB, which corresponds to a moderately hypofractionated treatment of the macroscopic recurrence. Based on the estimated low $\alpha / \beta$ ratio of the prostate, this would provide a theoretical biological advantage over conventional fractionation [38]. The use of IMRT withg SIB could even provide a better coverage of the target volume and protect adjacent tissues with low toxicity rates compared with conformal sequential treatments or a combination of conformal treatment and IMRT [39]. It will be interesting to observe the results of the ongoing MAPS trial (NCT01411345) comparing SRT with 68 Gy in 34 fractions versus $68 \mathrm{~Gy}$ in 34 fractions plus boost to MRI-guided macroscopic disease to $76.5 \mathrm{~Gy}$ (2.25 Gy per fraction).

We believe our results represent a reliable snapshot of the practice patterns for macroscopic local recurrence among Swiss radiation oncology centers. Although the participating radiation oncologists are representatives of each institution, adherence to these policies cannot be assured.

On top of the previously mentioned uncertainties, evolving genomic data have opened up a new landscape in $\mathrm{PCa}$ management. New models such as the analysis of patientspecific molecular signatures could allow the individualization of radiotherapy dose according to tumor radiosensitivity [40]. In addition, a relationship between quantitative mpMRI and gene expression in MRI-guided prostate biopsies has been recently presented [41]. In the future, after adequate validation all these emerging advances could further improve risk stratification and advance precision radiation oncology.

\section{Conclusion}

Our results show that among Swiss radiotherapy centers, there are different patterns of treatment when salvage radiotherapy is indicated for macroscopic local recurrence after prostatectomy. These data reflect the need for more standardized approaches and ultimately further research in this field.

Acknowledgements ADP and CP contributed equally to the manuscript. 


\section{Compliance with ethical guidelines}

Conflict of interest A. Dal Pra, C. Panje, T. Zilli, W. Arnold, K. Brouwer, H. Garcia, M. Glatzer, S. Gomez, F. Herrera, K. Kaouthar, A. Papachristofilou, G. Pesce, C. Reuter, H. Vees, D. Zwahlen, D. Engeler and P.M. Putora declare that they have no competing interests.

Ethical standards This article does not contain any studies with human participants or animals performed by any of the authors.

\section{References}

1. Ward JF, Moul JW (2005) Rising prostate-specific antigen after primary prostate cancer therapy. Nat Clin Pract Urol 2(4):174-182. doi:10.1038/ncpuro0145

2. Swanson GP, Hussey MA, Tangen CM, Chin J, Messing E, CanbyHagino E, Forman JD, Thompson IM, Crawford ED (2007) Predominant treatment failure in postprostatectomy patients is local: analysis of patterns of treatment failure in SWOG 8794. J Clin Oncol 25(16):2225-2229. doi:10.1200/JCO.2006.09.6495

3. Wiegel T, Bottke D, Steiner U, Siegmann A, Golz R, Storkel S, Willich N, Semjonow A, Souchon R, Stockle M, Rube C, Weissbach L, Althaus P, Rebmann U, Kalble T, Feldmann HJ, Wirth M, Hinke A, Hinkelbein W, Miller K (2009) Phase III postoperative adjuvant radiotherapy after radical prostatectomy compared with radical prostatectomy alone in $\mathrm{pT} 3$ prostate cancer with postoperative undetectable prostate-specific antigen: ARO 96-02/AUO AP 09/95. J Clin Oncol 27(18):2924-2930. doi:10.1200/JCO.2008.18. 9563

4. Thompson IM, Tangen CM, Paradelo J, Lucia MS, Miller G, Troyer D, Messing E, Forman J, Chin J, Swanson G, Canby-Hagino E, Crawford ED (2009) Adjuvant radiotherapy for pathological T3N0M0 prostate cancer significantly reduces risk of metastases and improves survival: long-term followup of a randomized clinical trial. J Urol 181(3):956-962. doi:10.1016/j.juro.2008.11.032

5. Bolla M, van Poppel H, Tombal B, Vekemans K, Da Pozzo L, de Reijke TM, Verbaeys A, Bosset JF, van Velthoven R, Colombel M, van de Beek C, Verhagen P, van den Bergh A, Sternberg C, Gasser T, van Tienhoven G, Scalliet P, Haustermans K, Collette L (2012) Postoperative radiotherapy after radical prostatectomy for high-risk prostate cancer: long-term results of a randomised controlled trial (EORTC trial 22911). Lancet 380(9858):2018-2027. doi:10.1016/ s0140-6736(12)61253-7

6. Tendulkar RD, Agrawal S, Gao T, Efstathiou JA, Pisansky TM, Michalski JM, Koontz BF, Hamstra DA, Feng FY, Liauw SL, Abramowitz MC, Pollack A, Anscher MS, Moghanaki D, Den RB, Stephans KL, Zietman AL, Lee WR, Kattan MW, Stephenson AJ (2016) Contemporary update of a multi-institutional predictive nomogram for salvage radiotherapy after radical prostatectomy. J Clin Oncol. doi:10.1200/jco.2016.67.9647

7. Fossati N, Karnes RJ, Cozzarini C, Fiorino C, Gandaglia G, Joniau S, Boorjian SA, Goldner G, Hinkelbein W, Haustermans K, Tombal B, Shariat S, Karakiewicz PI, Montorsi F, Van Poppel H, Wiegel T, Briganti A (2016) Assessing the optimal timing for early salvage radiation therapy in patients with prostate-specific antigen rise after radical prostatectomy. Eur Urol 69(4):728-733. doi:10.1016/j. eururo.2015.10.009

8. Amzalag G, Rager O, Tabouret-Viaud C, Wissmeyer M, Sfakianaki E, de Perrot T, Ratib O, Miralbell R, Giovacchini G, Garibotto V, Zilli $\mathrm{T}$ (2016) Target definition in salvage radiotherapy for recurrent prostate cancer: the role of advanced molecular imaging. Front Oncol 6:73. doi: 10.3389/fonc. 2016.00073

9. Carrie C, Hasbini A, de Laroche G, Richaud P, Guerif S, Latorzeff I, Supiot S, Bosset M, Lagrange JL, Beckendorf V, Lesaunier
F, Dubray B, Wagner JP, N'Guyen TD, Suchaud JP, Crehange G, Barbier N, Habibian M, Ferlay C, Fourneret P, Ruffion A, Dussart S (2016) Salvage radiotherapy with or without short-term hormone therapy for rising prostate-specific antigen concentration after radical prostatectomy (GETUG-AFU 16): a randomised, multicentre, open-label phase 3 trial. Lancet Oncol 17(6):747-756. doi:10.1016/ s1470-2045(16)00111-x

10. Ghadjar P, Hayoz S, Bernhard J, Zwahlen DR, Holscher T, Gut P, Guckenberger M, Hildebrandt G, Muller AC, Plasswilm L, Papachristofilou A, Stalder L, Biaggi-Rudolf C, Sumila M, Kranzbuhler H, Najafi Y, Ost P, Azinwi NC, Reuter C, Bodis S, Kaouthar K, Wust P, Thalmann GN, Aebersold DM (2015) Acute toxicity and quality of life after dose-intensified salvage radiation therapy for biochemically recurrent prostate cancer after prostatectomy: first results of the randomized trial SAKK 09/10. J Clin Oncol 33(35):4158-4166. doi:10.1200/jco.2015.63.3529

11. Shipley WU, Seiferheld W, Lukka HR, Major PP, Heney NM, Grignon DJ, Sartor O, Patel MP, Bahary JP, Zietman AL, Pisansky TM, Zeitzer KL, Lawton CA, Feng FY, Lovett RD, Balogh AG, Souhami L, Rosenthal SA, Kerlin KJ, Dignam JJ, Pugh SL, Sandler HM (2017) Radiation with or without Antiandrogen therapy in recurrent prostate cancer. N Engl J Med 376(5):417-428. doi:10. 1056/NEJMoa1607529

12. Radiation Therapy Oncology Group (2015) RTOG 0534 Protocol Information. https://www.rtog.org/ClinicalTrials/ProtocolTable/ StudyDetails.aspx?study=0534. Accessed 14 Feb 2017

13. Putora P, Panje CM, Papachristofilou A, Pra A, Hundsberger T, Plasswilm L (2014) Objective consensus from decision trees. Radiat Oncol 9(1):270. doi:10.1186/s13014-014-0270-y

14. Panje CM, Dal Pra A, Zilli T, Zwahlen DR, Papachristofilou A, Herrera FG, Matzinger O, Plasswilm L, Putora PM (2015) Consensus and differences in primary radiotherapy for localized and locally advanced prostate cancer in Switzerland: A survey on patterns of practice. Strahlenther Onkol 191(10):778-786. doi:10. 1007/s00066-015-0849-8

15. Michalski JM, Lawton C, El Naqa I, Ritter M, O’Meara E, Seider MJ, Lee WR, Rosenthal SA, Pisansky T, Catton C, Valicenti RK, Zietman AL, Bosch WR, Sandler H, Buyyounouski MK, Menard C (2010) Development of RTOG consensus guidelines for the definition of the clinical target volume for postoperative conformal radiation therapy for prostate cancer. Int J Radiat Oncol Biol Phys 76(2):361-368. doi:10.1016/j.ijrobp.2009.02.006

16. Poortmans P, Bossi A, Vandeputte K, Bosset M, Miralbell R, Maingon P, Boehmer D, Budiharto T, Symon Z, van den Bergh AC, Scrase C, Van Poppel H, Bolla M (2007) Guidelines for target volume definition in post-operative radiotherapy for prostate cancer, on behalf of the EORTC Radiation Oncology Group. Radiother Oncol 84(2):121-127. doi:10.1016/j.radonc.2007.07.017

17. D'Amico AV, Whittington R, Malkowicz SB, Schultz D, Blank K, Broderick GA, Tomaszewski JE, Renshaw AA, Kaplan I, Beard CJ, Wein A (1998) Biochemical outcome after radical prostatectomy, external beam radiation therapy, or interstitial radiation therapy for clinically localized prostate cancer. JAMA 280(11):969-974

18. Center MSKC Memorial Sloan Kettering Cancer Center (2017) Prostate cancer nomograms. https://www.mskcc.org/nomograms/ prostate. Accessed 14 Feb 2017

19. Partin AW, Yoo J, Carter HB, Pearson JD, Chan DW, Epstein JI, Walsh PC (1993) The use of prostate specific antigen, clinical stage and Gleason score to predict pathological stage in men with localized prostate cancer. J Urol 150(1):110-114

20. Roach M 3rd, Marquez C, Yuo HS, Narayan P, Coleman L, Nseyo UO, Navvab Z, Carroll PR (1994) Predicting the risk of lymph node involvement using the pre-treatment prostate specific antigen and Gleason score in men with clinically localized prostate cancer. Int J Radiat Oncol Biol Phys 28(1):33-37 
21. Hegemann NS, Morcinek S, Buchner A, Karl A, Stief C, Knuchel R, Corradini S, Li M, Belka C, Ganswindt U (2016) Risk of biochemical recurrence and timing of radiotherapy in pT3a NO prostate cancer with positive surgical margin: a single center experience. Strahlenther Onkol 192(7):440-448. doi:10.1007/s00066016-0990-z

22. Fossati N, Karnes RJ, Boorjian SA, Moschini M, Morlacco A, Bossi A, Seisen T, Cozzarini C, Fiorino C, Chiorda BN, Gandaglia G, Dell'Oglio P, Joniau S, Tosco L, Shariat S, Goldner G, Hinkelbein W, Bartkowiak D, Haustermans K, Tombal B, Montorsi F, Van Poppel H, Wiegel T, Briganti A (2016) Long-term impact of adjuvant versus early salvage radiation therapy in pT3N0 prostate cancer patients treated with radical prostatectomy: results from a multi-institutional series. Eur Urol. doi:10.1016/j.eururo.2016. 07.028

23. King CR (2012) The timing of salvage radiotherapy after radical prostatectomy: a systematic review. Int J Radiat Oncol Biol Phys 84(1):104-111. doi:10.1016/j.ijrobp.2011.10.069

24. Thompson IM, Valicenti RK, Albertsen P, Davis BJ, Goldenberg SL, Hahn C, Klein E, Michalski J, Roach M, Sartor O, Wolf JS Jr., Faraday MM (2013) Adjuvant and salvage radiotherapy after prostatectomy: AUA/ASTRO Guideline. J Urol 190(2):441-449. doi:10.1016/j.juro.2013.05.032

25. Cornford P, Bellmunt J, Bolla M, Briers E, De Santis M, Gross T, Henry AM, Joniau S, Lam TB, Mason MD, van der Poel HG, van der Kwast TH, Rouviere O, Wiegel T, Mottet N (2016) EAUESTRO-SIOG guidelines on prostate cancer. part II: treatment of relapsing, metastatic, and castration-resistant prostate cancer. Eur Urol. doi:10.1016/j.eururo.2016.08.002

26. Sobol I, Zaid HB, Haloi R, Mynderse LA, Froemming AT, Lowe VJ, Davis BJ, Kwon ED, Karnes RJ (2017) Contemporary mapping of post-prostatectomy prostate cancer relapse with 11C-choline positron emission tomography and multiparametric magnetic resonance imaging. J Urol 197(1):129-134. doi:10.1016/j.juro.2016. 07.073

27. Perera M, Papa N, Christidis D, Wetherell D, Hofman MS, Murphy DG, Bolton D, Lawrentschuk N (2016) Sensitivity, specificity, and predictors of positive 68 ga-prostate-specific membrane antigen positron emission tomography in advanced prostate cancer: a systematic review and Meta-analysis. Eur Urol 70(6):926-937. doi:10. 1016/j.eururo.2016.06.021

28. Pommier P, Chabaud S, Lagrange JL, Richaud P, Le Prise E, Wagner JP, Azria D, Beckendorf V, Suchaud JP, Bernier V, Perol D, Carrie C (2016) Is there a role for pelvic irradiation in localized prostate Adenocarcinoma? Update of the long-term survival results of the GETUG-01 randomized study. Int J Radiat Oncol Biol Phys 96(4):759-769. doi:10.1016/j.ijrobp.2016.06.2455

29. Roach M 3rd, DeSilvio M, Lawton C et al (2003) Phase III trial comparing whole-pelvic versus prostate-only radiotherapy and neoadjuvant versus adjuvant combined androgen suppression: Radiation Therapy Oncology Group 9413. J Clin Oncol 21:1904-1911

30. Song C, Kang HC, Kim JS, Eom KY, Kim IA, Chung JB, Hong SK, Byun SS, Lee SE (2015) Elective pelvic versus prostate bed-only salvage radiotherapy following radical prostatectomy: a propensity score-matched analysis. Strahlenther Onkol 191(10):801-809. doi: 10.1007/s00066-015-0872-9

31. Fossati N, Willemse PM, van den Bergh RC, Van den Broeck T, Yuan CY, Briers E, Bellmunt J, Bolla M, Cornford P, De Santis M, MacPepple E, Henry AM, Mason MD, Matveev VB, van der Poel HG, van der Kwast TH, Rouviere O, Schoots IG, Wiegel T, Lam
TB, Mottet N, Joniau S (2017) The benefits and harms of different extents of lymph node dissection during radical prostatectomy for prostate cancer: a systematic review. Eur Urol. doi:10.1016/j. eururo.2016.12.003

32. Dal Pra A, Cury FL, Souhami L (2010) Combining radiation therapy and androgen deprivation for localized prostate cancer - a critical review. Curr Oncol 17(5):28-38

33. Carrie C, Hasbini A, De Laroche G, Habibian M, Richaud P, Guérif S, Latorzeff I, Supiot S, Bosset M, Lagrange JL, Beckendorf V, Lesaunier F, Dubray B, Wagner JP, N'Guyen TD, Suchaud JP, Crehange G, Barbier N, Ruffion A, Dussart S (2015) Interest of short hormonotherapy (HT) associated with radiotherapy (RT) as salvage treatment for biological relapse (BR) after radical prostatectomy (RP): Results of the GETUG-AFU 16 phase III randomized trial - NCT00423475. J Clin Oncol 33(15_suppl):5006 (ASCO Annual Meeting (May 29 - June 2, 2015))

34. Zaorsky NG, Palmer JD, Hurwitz MD, Keith SW, Dicker AP, Den $\mathrm{RB}$ (2015) What is the ideal radiotherapy dose to treat prostate cancer? A meta-analysis of biologically equivalent dose escalation. Radiother Oncol 115(3):295-300. doi:10.1016/j.radonc.2015.05.011

35. Goenka A, Magsanoc JM, Pei X, Schechter M, Kollmeier M, Cox B, Scardino PT, Eastham JA, Zelefsky MJ (2011) Improved toxicity profile following high-dose postprostatectomy salvage radiation therapy with intensity-modulated radiation therapy. Eur Urol 60(6):1142-1148. doi:10.1016/j.eururo.2011.08.006

36. Ost P, Lumen N, Goessaert AS, Fonteyne V, De Troyer B, Jacobs F, De Meerleer G (2011) High-dose salvage intensity-modulated radiotherapy with or without androgen deprivation after radical prostatectomy for rising or persisting prostate-specific antigen: 5-year results. Eur Urol 60(4):842-849. doi:10.1016/j.eururo.2011. 04.021

37. Alongi F, Fiorino C, Cozzarini C, Broggi S, Perna L, Cattaneo GM, Calandrino R, Di Muzio N (2009) IMRT significantly reduces acute toxicity of whole-pelvis irradiation in patients treated with post-operative adjuvant or salvage radiotherapy after radical prostatectomy. Radiother Oncol 93(2):207-212. doi:10.1016/j.radonc.2009.08.042

38. Brenner DJ, Martinez AA, Edmundson GK, Mitchell C, Thames HD, Armour EP (2002) Direct evidence that prostate tumors show high sensitivity to fractionation (low alpha/beta ratio), similar to late-responding normal tissue. Int J Radiat Oncol Biol Phys 52(1):6-13

39. Li XA, Wang JZ, Jursinic PA, Lawton CA, Wang D (2005) Dosimetric advantages of IMRT simultaneous integrated boost for highrisk prostate cancer. Int J Radiat Oncol Biol Phys 61(4):1251-1257. doi:10.1016/j.ijrobp.2004.11.034

40. Scott JG, Berglund A, Schell MJ, Mihaylov I, Fulp WJ, Yue B, Welsh E, Caudell JJ, Ahmed K, Strom TS, Mellon E, Venkat P, Johnstone P, Foekens J, Lee J, Moros E, Dalton WS, Eschrich SA, McLeod H, Harrison LB, Torres-Roca JF (2016) A genomebased model for adjusting radiotherapy dose (GARD): a retrospective, cohort-based study. Lancet Oncol. doi:10.1016/s14702045(16)30648-9

41. Stoyanova R, Pollack A, Takhar M, Lynne C, Parra N, Lam LL, Alshalalfa M, Buerki C, Castillo R, Jorda M, Ashab HA, Kryvenko ON, Punnen S, Parekh DJ, Abramowitz MC, Gillies RJ, Davicioni E, Erho N, Ishkanian A (2016) Association of multiparametric MRI quantitative imaging features with prostate cancer gene expression in MRI-targeted prostate biopsies. Oncotarget 7(33):53362-53376. doi:10.18632/oncotarget.10523 